\title{
Childrens Views on Long-Term Screening for Type 1 Diabetes
}

\author{
Ulrica Swartling, Gert Helgesson, Johnny Ludvigsson, Mats G. Hansson and Anders \\ Nordgren
}

\section{Linköping University Post Print}

\section{Tweet}

N.B.: When citing this work, cite the original article.

Original Publication:

Ulrica Swartling, Gert Helgesson, Johnny Ludvigsson, Mats G. Hansson and Anders Nordgren, Childrens Views on Long-Term Screening for Type 1 Diabetes, 2014, Journal of Empirical Research on Human Research Ethics, (9), 4.

http://dx.doi.org/10.1177/1556264614544456

Copyright: University of California Press

http://www.ucpressjournals.com/

Postprint available at: Linköping University Electronic Press

http://urn.kb.se/resolve?urn=urn:nbn:se:liu:diva-111750 


\title{
Journal of Empirical Research on Human Research Ethics \\ http://jre.sagepub.com/
}

\section{Children's Views on Long-Term Screening for Type 1 Diabetes}

Ulrica Swartling, Gert Helgesson, Johnny Ludvigsson, Mats G. Hansson and Anders Nordgren Journal of Empirical Research on Human Research Ethics 2014 9: 1 originally published online 11 August 2014 DOI: $10.1177 / 1556264614544456$

The online version of this article can be found at: http://jre.sagepub.com/content/9/4/1

\author{
Published by: \\ (SAGE \\ http://www.sagepublications.com
}

Additional services and information for Journal of Empirical Research on Human Research Ethics can be found at:

Email Alerts: http://jre.sagepub.com/cgi/alerts

Subscriptions: http://jre.sagepub.com/subscriptions

Reprints: http://www.sagepub.com/journalsReprints.nav

Permissions: http://www.sagepub.com/journalsPermissions.nav

Citations: http://jre.sagepub.com/content/9/4/1.refs.html

>> Version of Record - Sep 16, 2014

OnlineFirst Version of Record - Aug 11, 2014

What is This? 


\title{
Children's Views on Long-Term Screening for Type I Diabetes
}

Journal of Empirical Research on Human Research Ethics 2014, Vol. 9(4) I-9 (C) The Author(s) 2014 Reprints and permissions: sagepub.com/journalsPermissions.nav DOI: I0.1 I77//5562646/4544456 jre.sagepub.com

(S)AGE

\author{
Ulrica Swartling ${ }^{1,2}$, Gert Helgesson ${ }^{3}$, Johnny Ludvigsson ${ }^{2}$, \\ Mats G. Hansson ${ }^{4}$, and Anders Nordgren ${ }^{2}$
}

\begin{abstract}
There are an increasing number of medical research studies involving children, including many long-term birth cohort studies. Involving children raises many issues, and little is known about children's own views. This study explored children's views $(N=5,85 \mathrm{I})$ on participation in a long-term screening study for type I diabetes. The results show that children 10 to 13 years of age have in general a positive attitude to pediatric research and emphasized trust in researchers. The children stressed the importance to receive information and to be involved in decisions. The children also reported feeling concerned about blood sampling and disease risk. Researchers involved in long-term pediatric research need to address these issues to promote involvement and decrease worry.
\end{abstract}

\section{Keywords}

research ethics, screening, children, type I diabetes, assent

There are an increasing number of medical research studies involving children, including many long-term birth cohort studies that follow children into adolescence (see Ries, 2007, for a comprehensive review). Research on children, conducted in a responsible way, may lead to new knowledge, treatments, and medicines that will benefit all children at some point. However, involving children in medical research raises many complex issues (Caldwell, Murphy, Butow, \& Craig, 2004; Kauffman, 2000; Ries, LeGrandeur, \& Caulfield, 2010; Ross, 2008).

Numerous studies have examined adult attitudes toward participation in medical research, but very little is known about children's own views on participation in medical research, for instance, how they feel about decision making, sampling, and risk identification. There are few data on the psychological impact of research participation on children, especially when children are screened for disease development - as is the case in many birth cohort studies. This is particularly true in the context of type 1 diabetes screening, where several ongoing studies follow large numbers of children to study the development of type 1 diabetes in child cohorts with, as well as without, genetic susceptibility (Johnson, 2011; Hens, Nys, Cassiman, \& Dierickx, 2011; Ries, 2007; Swartling, Hansson, Ludvigsson, \& Nordgren, 2011). Some of these studies, for example, the international TEDDY (The Environmental Determinants of Diabetes in the Young) study, involve screening genetically high-risk children and monitoring them through extensive research protocols for more than a decade (Hagopian et al., 2011).
Some studies have addressed issues in research ethics, such as factors involved in children's decision-making processes. Some show that children, when asked, are positive about participation in research that is not directly beneficial to themselves (Wendler, Abdoler, Wiener, \& Grady, 2012; Wendler \& Jenkins, 2008). Others have examined factors influencing decisions about whether to participate - providing children and adolescents with a number of research scenarios (Cherill et al., 2007; Mukattash, Trew, Hawwa, \& McElnay, 2012; Varma, Jenkins, \& Wendler, 2008). Others have studied factors related to informed consent and children's understanding of research information (Bernhardt, Tambor, Fraser, Wissow, \& Geller, 2003; Brody, Scherer, AnNett, \& Pearson-Bish, 2003; Chappuy, Doz, Blanche, Gentet, \& Tréluyer, 2008). Studies by Chappuy et al. (2008) and Tait, Voepel-Lewis, and Malviya (2003) showed that children have an incomplete understanding of the information provided to them, indicating the importance of developing appropriate procedures for informing, involving, and

\footnotetext{
'Lund University, Sweden

${ }^{2}$ Linköping University, Sweden

${ }^{3}$ Karolinska Institutet, Solna, Sweden

${ }^{4}$ Uppsala University, Sweden

Corresponding Author:

Ulrica Swartling, Division of Diabetes and Celiac disease, Department of Clinical Sciences, Skåne University Hospital (SUS), 20502 Malmö, Sweden.

Email: ulrica.swartling@med.lu.se
} 
getting valid assents from competent children involved in research.

This is a particular challenge within the context of longterm natural history and screening studies, such as screening studies for type 1 diabetes. These studies typically involve children and families for many years, from birth up to adolescence. Apart from the difficulties already mentioned, as well as practical challenges, these studies bring in a number of ethical issues regarding assent and consent, as the children grow older during research participation and become increasingly competent decision makers (Miller, Drotar, \& Kodish, 2004; Ries et al., 2010; Rossi, Reynolds, \& Nelson, 2003). Researchers involved in such studies will reach the point where the parents' original consent needs to be complemented by the children's assent, and later, entirely replaced when children can give proper consent. Studies also show that children want to be involved in decisions about research (Wendler \& Jenkins, 2008). Other studies show that balancing the formal rights and wishes of parents with the child's increasing rights may prove a challenging issue unless there are prior appropriately developed strategies (Swartling, Helgesson, Hansson, \& Ludvigsson, 2009).

To address these issues in the context of long-term screening for type 1 diabetes, and in an attempt to gather pilot data on the psychological consequences, we designed this study to explore 10- to 13-year-old boys' and girls' views on medical research, trust, information, decision making, and views on data sampling and risk identification. Most of the 5,851 children in our study had previous long-term experience of natural history screening for type 1 diabetes, while the remaining child cohort had no previous experience, providing a unique opportunity to study the views of a large cohort of children from the general population, as well as of children with a family history of type 1 diabetes.

\section{Method}

\section{Participants}

The data presented in this article originate from children participating in the Swedish ABIS (All Babies of Southeast Sweden) study, a screening study for the development of type 1 diabetes and other immune mediated diseases. The ABIS research protocol has been described in greater detail elsewhere (Gustafsson Stolt, Helgesson, Liss, Ludvigsson, \& Svensson, 2005; Helgesson, Hansson, Ludvigsson, \& Swartling, 2009). Between 1997 and 1999, 17, 000 parents consented to participate in the ABIS study $(78.6 \%$ of the general birth cohort) at the time of delivery. From birth, samples (blood, urine, hair, and stool) were collected from the children at regular intervals: birth, 1 year, 2 to 3,5 to 6 , and 8 years. The parents completed questionnaires at these points in time, mapping the family's natural history with questions regarding eating habits, physical activity, psychosocial situation, physical environment, infections, and diseases. The children received their first minor questionnaire when they were 8 years old, containing questions on general psychological issues, including body perception (Koch, Ludvigsson, \& Sepa, 2008).

Before the children reached the age of 5, the main information was provided to the parents through information letters and through the ABIS website (www.abis-studien.se). When the children were 5 years old, they received a short brochure with pictures and brief sentences describing the ABIS study. When they turned 8, additional information to the children was provided through the website in a special section for kids. The web pages contained more in-depth information about the study and its methods, and clarified that the study aimed to identify factors leading to type 1 diabetes, including children at risk. Before the 10- to 13-year data collection (see below), the children were provided with a more detailed letter of information, and a brief video made for information purposes (provided at the website). However, we do not know the extent to which children have had accessed (had read or seen) the information.

\section{Procedures}

When the children were 10 to 13 years of age, the data sampling was designed differently compared with the previous occasions, where the sample kits and the questionnaires had been mailed directly to the parents. Data collection started with questionnaires to the child and parents and the collection of a sample of hair from the child. The data collection was carried out in two waves (2009-2011). The first data collection was accomplished with the aid of the schools in the region. After initial consent (head master and class teacher), research material was sent to the schools. The children were asked to take home a package with written information (including the video link), questionnaires to the parents, and opt-out notes. If appropriate, the parents (and the children) were shown the video during parental meetings. The children were to receive additional information through the teachers at school and from parents at home. Those parents who did not want their child to participate were asked to complete the form and give it to the teacher. The day and time for completing the ABIS child questionnaire were left to the teacher to decide. Children were included in the 10- to 13-year control group based on either (a) parental consent implied by the parents filling out the parental questionnaire before the child took part in any ABIS activities at school, and on the condition that they had not signed and sent in the opt-out note, or (b) parental written consent (a signed and submitted consent form for the child). The second data collection included mailed packages of questionnaires (child and parental) to earlier "ABIS families" that had completed at least two questionnaires prior to the 10- to 13-year child questionnaire, and where at least one blood sample had been collected. 
Table I. Children's Views on Participation in a Medical Research Screening Study $(N=5,85 I)$.

\begin{tabular}{|c|c|c|c|c|c|c|}
\hline How important do you think it is ... & $n$ & $\begin{array}{l}\text { Not at all } \\
\text { important }\end{array}$ & $\begin{array}{l}\text { Less } \\
\text { important }\end{array}$ & $\begin{array}{l}\text { Rather } \\
\text { important }\end{array}$ & $\begin{array}{l}\text { Very } \\
\text { important }\end{array}$ & \\
\hline $\begin{array}{l}\text { To do research on why children (and adults) } \\
\text { get sick }\end{array}$ & 5,610 & 0.9 & 4.8 & 27.2 & 67.0 & \\
\hline Boys/girls & & I.3-0.6 & $5.8-4.0$ & $29.1-25.4$ & $63.8-70.1$ & $* * *$ \\
\hline Previous ABIS child/first time & & $0.7-1.7$ & $4.9-4.7$ & $27.0-27.7$ & $67.4-65.8$ & ns \\
\hline $\begin{array}{l}\text { To do research on new medicines to } \\
\text { children (and adults) }\end{array}$ & 5,617 & 0.6 & 1.3 & 12.5 & 85.7 & \\
\hline Boys/girls & & $0.8-0.3$ & $1.6-1.0$ & $15.0-10.0$ & $82.5-88.7$ & $* * *$ \\
\hline Previous ABIS child/first time & & $0.3-1.2$ & I.4-I.I & $12.1-13.4$ & $86.2-84.3$ & $* * *$ \\
\hline $\begin{array}{l}\text { That you (and your parents) participate in } \\
\text { medical research, such as the ABIS study }\end{array}$ & 5,422 & 2.7 & 17.4 & 54.6 & 25.3 & \\
\hline Boys/girls & & $3.6-1.9$ & $19.9-15.0$ & $52.6-56.5$ & $24.0-26.6$ & $* * *$ \\
\hline Previous ABIS child/first time & & $2.2-3.5$ & $16.2-20.5$ & $55.0-53.2$ & $26.3-22.8$ & $* * *$ \\
\hline $\begin{array}{l}\text { That you can trust the researchers when you } \\
\text { participate in research? }\end{array}$ & 5,592 & 0.8 & 2.9 & 29.3 & 67.0 & \\
\hline Boys/girls & & I.I-0.5 & $3.4-2.4$ & $32.1-26.7$ & $63.4-70.4$ & $* * *$ \\
\hline Previous ABIS child/first time & & $0.7-1.1$ & $2.8-3.3$ & $29.1-30.1$ & $67.5-65.5$ & ns \\
\hline
\end{tabular}

Note. $A B I S=$ All Babies of Southeast Sweden; ns = statistically non-significant.

$* * * p<.001 . * * p<.05$.

The 10- to 13-year questionnaire data collection was thus mainly accomplished at school. No blood sampling took place. However, after having completed the questionnaire, the child was asked to cut off a piece of hair and to put it in an envelope at the back of the questionnaire.

\section{Measures}

The clinical part of the ABIS Child questionnaire consisted of 60 questions on eating habits, sleep, diet, physical activity, and quality of life. The remaining part consisted of questions addressing the four key themes: attitudes to medical research and researchers, provision of information, decision making and assent/consent, and attitudes/feelings about data sampling that our earlier research on screening for type 1 diabetes research had identified (Helgesson \& Swartling, 2008; Swartling et al., 2009; Swartling, Helgesson, Ludvigsson, \& Hansson, 2008). You may find the questionnaire in Swedish and also translated to English at jre.sagepub.com/supplemental. The main variables that we used for the analyses presented in this article are demographics, views on ABIS participation and pediatric issues, views on information, decision making, and impact of participation.

Demographics. Child characteristics included age and gender, and whether the mother or the child had type 1 diabetes. Binary variables were constructed for the analyses.

$A B I S$ participation. If a child had participated (with his or her parents) in the ABIS study on at least one previous occasion, we identified that child as an "ABIS-child."
Views on general pediatric research issues. This was assessed through four questions (see Table 1), constructed as Likerttype scales ranging from not at all important to very important and addressed the children's views on how important they regarded issues related to pediatric research: pediatric research in general, research on new drugs and medicines, child participation, and trust.

Views on information and decision making. We used three items to assess the children's views. The first item (see Table 2) asked the children to state how important they think it is to receive information about the research they participate in (Likert-type scale question [1-4], ranging from not at all important to very important). The second item asked them to state whether they were satisfied with the information they have received. The answer alternatives ranged from definitely enough to definitely not enough. The third item asked the respondents to state preferred ways of receiving information through a fixed set of alternatives (see Online Appendix 1 [in English] or Online Appendix 2 [in Swedish] for full range of alternatives).

Views on decision making. A first item asked the children how important they thought it was to be involved in decisions about whether or not to participate. This item was constructed as a Likert-type scale question (1-4), and ranged from not at all important to very important. The second item asked for their views on who should decide regarding participation in data sampling (questionnaire and biological sampling of blood and hair. Fixed alternatives were provided: "my parents and I together," "myself only," "my 
Table 2. Children's Views on Information and Involvement in Decision Making $(N=5,85 \mathrm{I})$.

\begin{tabular}{|c|c|c|c|c|c|c|}
\hline How important do you think it is. . . & $n$ & $\begin{array}{l}\text { Not at all } \\
\text { important }\end{array}$ & $\begin{array}{l}\text { Less } \\
\text { important }\end{array}$ & $\begin{array}{l}\text { Rather } \\
\text { important }\end{array}$ & $\begin{array}{l}\text { Very } \\
\text { important }\end{array}$ & \\
\hline $\begin{array}{l}\text { That you receive your own information when } \\
\text { you are participating in research }\end{array}$ & 5,553 & 2.2 & 10.3 & 37.7 & 49.8 & \\
\hline Boys/girls & & $2.8-1.5$ & II.5-9.2 & $37.4-38.0$ & $48.2-51.2$ & $* * *$ \\
\hline \multirow[t]{2}{*}{ Previous ABIS child/first time } & & $1.9-2.9$ & $10.8-9.0$ & $37.5-38.4$ & $49.7-49.8$ & ns \\
\hline & & $\begin{array}{l}\text { Absolutely not } \\
\text { enough }\end{array}$ & $\begin{array}{l}\text { Not really } \\
\text { enough }\end{array}$ & Enough & $\begin{array}{l}\text { Absolutely } \\
\text { enough }\end{array}$ & \\
\hline $\begin{array}{l}\text { That you are involved in decisions when you } \\
\text { participate in research }\end{array}$ & 5,574 & 1.6 & 6.8 & 29.7 & 61.9 & \\
\hline Boys/girls & & $2.2-1.0$ & 7.9-5.7 & $31.5-28.0$ & $58.4-65.3$ & $* * *$ \\
\hline Previous ABIS child/first time & & $1.5-1.8$ & $7.1-6.1$ & $29.8-29.6$ & $61.7-62.6$ & ns \\
\hline $\begin{array}{l}\text { Are you satisfied with the information you have } \\
\text { received? }\end{array}$ & 5,464 & 4.1 & 13.2 & 56.4 & 26.3 & \\
\hline Boys/girls & & 4.1-4.2 & $12.9-3.5$ & $57.1-55.6$ & $25.9-26.7$ & ns \\
\hline Previous ABIS child/first time & & $4.5-3.1$ & $13.9-1 \mid .5$ & $56.4-56.4$ & $25.2-29.0$ & $* * *$ \\
\hline \multicolumn{6}{|l|}{ How would you like to receive information } & \\
\hline & & $\%$ & $\%$ & $\%$ & $\%$ & \\
\hline Oral by parents & & 62.6 & 52.7 & 64.4 & 60.9 & \\
\hline Oral by researchers & & 16.0 & 14.3 & 17.0 & 15.0 & \\
\hline Written letter/brochure to me personally & & 37.2 & 25.6 & 44.1 & 30.5 & \\
\hline Through the Internet (website/email) & & 17.3 & 12.1 & 17.5 & 17.0 & \\
\hline $\begin{array}{l}\text { Who do you think should decide about whether } \\
\text { you should }\end{array}$ & & My parents & $\begin{array}{l}\text { Myself and I } \\
\text { together only }\end{array}$ & $\begin{array}{l}\text { My parents } \\
\text { only }\end{array}$ & $\begin{array}{l}\text { Researchers } \\
\text { only }\end{array}$ & \\
\hline a. Complete questionnaires & 5,721 & 51.9 & 35.5 & 6.2 & 3.2 & \\
\hline Boys/girls & & $48.2-55.5$ & $37.4-33.6$ & $7.3-5.2$ & $3.7-2.7$ & \\
\hline Previous ABIS child/first time & & $52.5-50.1$ & $35.9-34.4$ & 4.I-7.7 & $3.1-3.5$ & \\
\hline b. Leave a hair sample & 5,721 & 53.8 & 31.9 & 5.8 & 10.5 & \\
\hline Boys/girls & & $50.5-57.9$ & $32.9-30.9$ & $7.0-4.6$ & 7.1-4.8 & \\
\hline Previous ABIS child/first time & & $55.7-48.3$ & $30.9-34.8$ & $5.3-7.2$ & $5.8-6.1$ & \\
\hline c. Leave a blood sample & 5,729 & 65.1 & 16.2 & 5.1 & 10.5 & \\
\hline Boys/girls & & $61.0-69.1$ & $18.3-14.3$ & $6.4-3.9$ & II.2-9.6 & \\
\hline Previous ABIS child/first time & & $66.4-61.7$ & $17.1-14.0$ & $4.2-7.6$ & $9.6-12.3$ & \\
\hline
\end{tabular}

Note. $\mathrm{ABIS}=$ All Babies of Southeast Sweden; $\mathrm{ns}=$ statistically non-significant. $* * * p<.001 . * * p<.05$.

parents only," and "researchers only." In the questionnaire, these alternatives were presented in random order.

Child (self-) assessment of "psychological impact" through participation in the 10- to 13-year control. The children were asked to state their feelings regarding the following:

a. participating in medical research, such as the ABIS study,

b. answering questions in the questionnaire,

c. leaving a hair sample,

d. leaving a blood sample (in the future), and

e. (potential) findings on risk to develop a disease (diabetes).
Items were all constructed as Likert-type scales with alternative Options 1 to 4, ranging from not at all important to very important.

\section{Results}

\section{Participant Demographics}

The ABIS 10- to 13-year child questionnaire was completed by 5,851 children. Of these, $72.3 \%(n=4,230)$ had participated earlier in the ABIS study, while the remaining $27.7 \%$ $(n=1,621)$ participated for the first time. An almost equal proportion of girls and boys participated: $50.3 \%$ were girls and $49.7 \%$ were boys. The children's age ranged from 10 to 
14 years: $24 \%$ of the children were 10 to 11 years, $71.9 \%$ were between 12 and 13 years, and $3.9 \%$ of the children had already turned $14(M=12.16, S D=0.860)$. As the number of respondents being 14 years old was less than $5 \%$ of the total sample, we henceforth use the expression " 10 to 13 years of age" to cover all participants throughout the article. Of the children participating in the ABIS study earlier, 6.7\% had a mother with type 1 diabetes, and $2.9 \%$ had developed type 1 diabetes themselves (father data unknown). Of the whole cohort, 36\% report to "know"/know of someone with "diabetes." Due to the study design, socio-demographic data of the entire cohort were not available.

\section{Attitudes to Medical Research}

Initially, the majority of the responding children reported that research on why people get sick and on drugs is very important (65.0\%-85.7\%). Girls marked very important more frequently than boys, the difference being statistically significant. When asked about participation in medical research, such as the ABIS study, a significantly lower number, $25.3 \%$, of children marked very important, compared with the statements on research in general. Children with earlier experience of the ABIS study were more positive than children in general.

Trust in researchers was emphasized by all children: $97 \%$ of the children marked trust "rather important" or "very important." Girls put a significant degree more emphasis on trust than boys: $70.4 \%$ of the girls marked "very important" - compared with $63.4 \%$ of the boys. We found no differences based on earlier ABIS participation.

\section{Views on Information}

The majority of children regarded it important both to receive research information and to be involved in decisions about participation. More than $85 \%$ of both boys and girls state receiving information was "rather important" or "very important." More than $90 \%$ also consider it to be important to be involved in decisions. Girls more frequently emphasized the importance compared with boys. There were no differences between those with previous ABIS experience and first-time participants, or between whether the child had a family history of type 1 diabetes or not.

The second item on information assessed the children's views on the information they had received: a letter of information and a short video. The children were asked whether they were satisfied with the information provided. The results show that while the majority of the children were satisfied with the information provided, $17.3 \%$ $(=945)$ stated that the information was "not really enough" or "definitely not enough." We found no significant differences between the views of girls and boys, or regarding whether the child or the mother had type 1 diabetes.
However, "ABIS children" were more dissatisfied with the information (18.4\%) than children in families with no prior experience of the study (14.6\%), as were older children (1214 years)

The majority of children preferred to receive oral information through their parents, with brochures and/or letters as the secondarily preferred option (among a fixed set of options). Only a minority wished to receive information through a website. Girls and children with earlier experience from the ABIS study more frequently preferred being informed by their parents. Girls were more positive toward receiving information through brochures and/or letters compared with boys.

\section{Views on Decision Making}

The majority of the respondents wanted to be involved in decision making: $91.6 \%(n=5,106)$ of the children marked this as "rather important" or "very important." Girls significantly more frequently emphasized the importance of being involved in decisions about research in general, with $65.3 \%$ marking "very important," compared with boys (58.4\%). No significant differences were found when comparing earlier ABIS children with first-time participant children.

The children were asked similar questions about decision making in the context of the ABIS data sampling. At the time of the 10- to 13-year questionnaire, the children had two experiences from data sampling: the questionnaire itself and the cutting of a piece of hair (done at the same time as completing the questionnaire). The question on blood sampling was added because the ABIS group planned at a later phase to ask for parental consent.

Table 2 shows that a minority of the children report wanting to decide for themselves, regardless of sampling type.

Regarding the child questionnaires, the majority of the children $(51.9 \%)$ wanted to decide together with their parents, while $35.5 \%$ of the children wanted to decide for themselves; $3.2 \%$ stated that researchers only should decide, and $6.2 \%$ of the children stated that they want their parents to decide. Girls significantly more frequently emphasize shared decision making than boys (55.5\% compared with $48.2 \%)$.

Regarding sampling of hair, 53.8\% stated that they want to decide together with their parents, $31.9 \%$ expressed wanting to decide for themselves, while a minority wished to leave the decision to their parents $(5.8 \%)$ or to the researchers (10.5\%). Also in this context, girls emphasized significantly more shared decision making than boys (57.0\% compared with 50.5\%), with slightly less emphasis on deciding for themselves. Children with earlier ABIS experience significantly more frequently preferred shared decision making (55.7\%) compared with first-time participants (48.3\%). Regarding the blood sampling, $65.1 \%$ of the 
Table 3. Children's Reports on Feelings Toward Data Collection and Analyses $(N=5,85 \mathrm{I})$.

\begin{tabular}{|c|c|c|c|c|}
\hline $\begin{array}{l}\text { When you think about ... how do } \\
\text { you feel then? }\end{array}$ & $n$ & Very/rather worried & Rather/very calm & \\
\hline \multicolumn{5}{|c|}{ Participating in research, like the ABIS study } \\
\hline All & 5,641 & 5.0 & 95.0 & \\
\hline Boys/girls & & $5.7-4.3$ & $94.3-95.7$ & $* *$ \\
\hline Previous ABIS child/first time & & $3.8-8.3$ & $96.2-91.7$ & $* * *$ \\
\hline \multicolumn{5}{|l|}{ Answering questions such as these } \\
\hline All & 5,620 & 3.5 & 96.5 & \\
\hline Boys/girls & & $4.0-3.2$ & $96.0-96.8$ & ns \\
\hline Previous ABIS child/first time & & $3.1-5.1$ & $96.9-94.9$ & $* * *$ \\
\hline \multicolumn{5}{|l|}{ Leaving a hair sample } \\
\hline All & 5,562 & II.I & 98.9 & \\
\hline Boys/girls & & 8.3-13.4 & $91.7-86.6$ & $* * *$ \\
\hline ABIS child/first time ABIS & & $2.1-4.5$ & $97.9-95.5$ & *** \\
\hline \multicolumn{5}{|c|}{ That you may be asked to leave a blood sample (in the future) } \\
\hline All & 5,616 & 29.5 & 70.5 & \\
\hline Boys/girls & & 24.0-34.6 & $76.0-65.4$ & $* * *$ \\
\hline Previous ABIS child/first time & & 27.4-35.0 & $72.6-65.0$ & $* * *$ \\
\hline \multicolumn{5}{|c|}{ That the researchers in ABIS want to find out whether you have a higher risk of getting a disease (diabetes) } \\
\hline All & 5,626 & 26.0 & 74.0 & \\
\hline Boys/girls & & $25.8-26.1$ & $74.2-73.9$ & ns \\
\hline Previous ABIS child/first time & & $24.0-31.3$ & $76.0-68.7$ & $* * *$ \\
\hline
\end{tabular}

Note. $\mathrm{ABIS}=$ All Babies of Southeast Sweden; ns = statistically non-significant. $* * * p<.001$. *** $<$.05.

respondents emphasized shared decision making, $16.2 \%$ wanted to decide for themselves, while a minority wanted to leave the decision to the parents or the researchers. We found no correlations to type 1 diabetes in the child or the mother.

\section{Attitudes and Feelings Toward Data Sampling}

As Table 3 displays, a majority reported feeling calm about participation in the ABIS study.

Approximately $88.8 \%$ reported feeling calm about leaving the hair sample, while $11.2 \%$ reported being "very worried" or "rather worried." Concerning future blood draw, $70.5 \%$ reported feeling calm, while $29.5 \%$ reported feeling concerned. Girls were significantly more concerned than boys about the blood draw. Regarding high-risk identification, $26 \%$ reported being worried. "ABIS children" to a significantly lesser extent expressed being worried about participation in general and about completing the questionnaire.

In general, girls, as well as first-time participants, were more concerned about the biological sampling. First-time participants were also significantly more frequently concerned about high-risk identification. Children who had developed type 1 diabetes or children with a mother with the disease were not more worried than other children.

\section{Discussion}

We have presented the attitudes and views of more than 5,500 children between 10 and 13 years of age participating in a long-term screening study for type 1 diabetes. In summary, the analyses show that the majority of the children report being supportive of pediatric research and consider such research as important, regardless of age, gender, or earlier experience of research participation. When the research was specified ("participation in research as the ABIS study"), the number of children positive about participation declined. The children emphasized the importance of feeling trust toward researchers involved. We also found that children emphasize wanting to be informed and involved in decisions relating to research participation. A majority wished to decide about their participation together with their parents (more than 50\%) rather than deciding for themselves or leaving the decisions to others. Girls preferred shared decision making significantly more frequently than boys, who were more willing to leave the decisions to others.

Finally, our analyses showed, that while the majority of participating children reported feeling calm, some children reported worrying about the biological sampling (hair and blood) and high-risk identification (20\%-25\%). Completing questionnaires and leaving a piece of hair did not raise the 
same concerns - although girls expressed concern about cutting their hair. Girls and children with no previous experience from the ABIS study were significantly more concerned.

That so many children, with and without earlier experience, state being positive to medical research, is a reasonable indication that this is a general attitude among children of this age - and not specific to certain groups. However, that children state being less positive to research when the ABIS study is mentioned may be an indication that children generally have difficulties in understanding what medical research is about. This positive basic attitude is, however, important and researchers should take appropriate steps to support this attitude.

We also saw that children, regardless of background, age, or gender, expressed a wish to be informed themselves and to be involved in decision making. These results support recommendations and are in line with earlier research, including our own (Alderson, Sutcliffe, \& Curtis, 2006; Swartling et al., 2009; Swartling et al., 2008). The results also support the idea that a shared decision-making model is preferable (in long-term research) when children grow older (Alderson et al., 2006; Ries, 2007). Different "models" or strategies for informing and engaging the children according to their ages should respect their right to be involved so that their voices can be heard and concerns and wishes addressed.

In this respect, the data highlight the quite substantial challenge for researchers: Children growing up during their research participation hold potential for disagreement within families on children's involvement in decision making about research participation - not only regarding enrollment but also regarding other aspects of research participation, such as parent/child communication and data sampling. Our earlier research on the adult cohort of the ABIS study has repeatedly shown that parents are positive toward informing their children about the research, but much less positive toward leaving the decision making to their children or even sharing it with them. More than $40 \%$ of the parents reported being against or unsure of whether their child should be allowed to decide about matters relating to their participation-findings also supported by other studies (Swartling et al., 2009; Swartling et al., 2008; Varma et al., 2008). In addition, the study by Tercyak, Swartling, Mays, Johnson, and Ludvigsson (2013) showed that a large proportion of ABIS parents assess their child's knowledge about the ABIS study as low. This is an indication that many parents do not engage in communication about research with their children, and that researchers may need to develop tools appropriate for both parents and children, so that children can be adequatly informed. This may prove challenging in the future for the quite large number of currently ongoing long-term cohort studies. These investigators are about to face the transition from consent by parents into active decision making by the children themselves (who are initially asked to affirm being positive and later to provide a genuine consent). Investigators should be aware of these issues and find ways to address these issues and potential disagreements when designing long-term information strategies, engaging the growing children in the research process, and later, soliciting assent/consent.

In this respect, it is of vital importance that researchers design and implement information strategies that take into account the growing child population capacities and wishes to be informed and involved. Research would benefit from studies investigating and assessing the information protocols within long-term research.

We also found that some children reported being worried about biological sampling and high-risk identification, while expressing less concern about participation in general and the completion of questionnaires. A limitation with our study regarding these findings is that two of these questions were merely hypothetical (those regarding blood sampling and high-risk identification), and that people in general are more afraid of things that they do not know anything about and respond to questions accordingly.

However, researchers involved in pediatric research, and specifically long-term cohort studies involving children, need to be aware of these potential worries and include communication strategies for how and when to provide ageadjusted information addressing children's concerns. Appropriate information strategies may not only decrease worry but also strengthen trust and meet the wish for information and involvement. More research is needed on screening studies where more invasive procedures are used.

\section{Best Practices}

In medical research on children, it is important to (a) provide children with information about the study and about study participation, (b) encourage shared decision making but also to explore what forms of shared decision making are preferable, and (c) pay particular attention to aspects of research participation in the specific study that may worry young participants, and to find ways to describe these aspects in a way that put children in a position where they, as far as possible, understand the options.

\section{Research Agenda}

More research on shared decision making involving children is needed, including what forms of shared decision making are preferable in this specific context. The present study shows that children aged 10 to 13 stress the importance of receiving research information. The pedagogicaland ethical - challenge in relation to this is to improve ways to get the relevant information across. This problem is indeed common to all research involving human research 
subjects on a voluntary basis but is especially poignant in relation to individuals with less life experience and a less developed ability to understand things that they have not experienced before. Information about study participation should cover not only what will happen in practice if you participate (which may be visually shown to a considerable extent) but also what is at stake in terms of risks and benefits in the narrow and wider perspectives.

\section{Educational Implications}

The present study identifies a number of aspects on research involving children that have educational implications: (a) It gives support to the view that children generally trust researchers and have a positive attitude toward research participation; (b) it shows that children find it important to receive study information; and (c) it also shows that there may be aspects of the study participation for which they feel concern. A general point to get across in the educational context is that it is important to find workable ways to inform children about what it means to participate in research and that information and discussion of the aspects of such participation that worries the children the most are particularly important.

\section{Acknowledgment}

We are deeply indebted to the children who participated in this study.

\section{Declaration of Conflicting Interests}

The author(s) declared no potential conflicts of interest with respect to the research, authorship, and/or publication of this article.

\section{Funding}

The author(s) disclosed receipt of the following financial support for the research, authorship, and/or publication of this article: This project was financially supported by the Swedish Research Council(VR), The Swedish Diabetes Foundation(Diabetesfonden), and the Swedish Child Diabetes Foundation (Barndiabetesfonden).

\section{References}

Alderson, P., Sutcliffe, K., \& Curtis, K. (2006). Children as partners with adults in their medical care. Archives of Diseases in Childhood, 91, 300-303.

Bernhardt, B. A., Tambor, E. S., Fraser, G., Wissow, L. S., \& Geller, G. (2003). Parents' and children's attitudes toward the enrollment of minors in genetic susceptibility research: Implications for informed consent. American Journal of Medical Genetics A, 1(116A), 315-323.

Brody, J. L., Scherer, D. G., Annett, R. D., \& Pearson-Bish, M. (2003). Voluntary assent in biomedical research with adolescents: A comparison of parent and adolescent views. Ethics \& Behavior, 13, 79-95.
Caldwell, P. H. Y., Murphy, S. B., Butow, P. N., \& Craig, J. C. (2004). Clinical trials in children. Lancet, 364, 803-811.

Chappuy, H., Doz, F., Blanche, S., Gentet, J. C., \& Tréluyer, J. M. (2008). Children's views on their involvement in clinical research. Pediatric Blood \& Cancer, 50, 1043-1046.

Cherill, J., Hudson, H., Cocking, C., Unsworth, V., Franck, L., McIntyre, J., \& Choonara, I. (2007). Clinical trials: The viewpoint of children. Archive of Disease in Childhood, 92, 712-713.

Gustafsson Stolt, U., Helgesson, G., Liss, P.-E., Ludvigsson, J., \& Svensson, T. (2005). Information and informed consent in a longitudinal screening involving children: A questionnaire survey. European Journal of Human Genetics, 13, 376-383.

Hagopian, W. A., Erlich, H., Lernmark, A., Rewers, M., Ziegler, A. G., \& Simell, O., ... TEDDY Study Group. (2011). The Environmental Determinants of Diabetes in the Young (TEDDY): Genetic criteria and international diabetes risk screening of 421,000 infants. Pediatric Diabetes, 12(8), 733-43.

Helgesson, G., Hansson, M. G., Ludvigsson, J., \& Swartling, U. (2009). Practical matters, rather than lack of trust, motivate non-participation in a long-term cohort trial. Pediatric Diabetes, 10, 408-412.

Helgesson, G., \& Swartling, U. (2008). Views on data use, confidentiality, and consent in a predictive screening involving children. Journal of Medical Ethics, 34, 206-209.

Hens, K., Nys, H., Cassiman, J. J., \& Dierickx, K. (2011). The storage and use of biological tissue samples from minors for research: A focus group study. Public Health Genomics, 14(2), 68-76.

Johnson, S. B. (2011). Psychological impact of screening and prediction in type 1 diabetes. Current Diabetes Report, 11, 454-459.

Kauffman, R. E. (2000). Clinical trials in children: Problems and pitfalls. Paediatric Drugs, 2, 411-418.

Koch, F. S., Ludvigsson, J., \& Sepa, A. (2008). Body dissatisfaction measured with a figure preference task and self-esteem in 8 year old children: A study within the ABIS-project. Clinical Medicine: Pediatrics, 2, 13-26.

Miller, V. A., Drotar, D., \& Kodish, E. (2004). Children's competence for assent and consent: A review of empirical findings. Ethics \& behavior, 14, 255-295.

Mukattash, T., Trew, K., Hawwa, A. F., \& McElnay, J. C. (2012). Children's views on unlicensed/off-label paediatric prescribing and paediatric clinical trials. European Journal of Clinical Pharmacology, 68, 141-148.

Ries, N. M. (2007). Growing up as a research subject: Ethical and legal issues in birth cohort studies involving genetic research. Health Law Journal, 15, 1-41.

Ries, N. M., LeGrandeur, J., \& Caulfield, T. (2010). Handling ethical, legal, and social issues in birth cohort studies involving genetic research: Responses from studies in six countries. BMC Medical Ethics, 11(1), Article 4.

Ross, L. F. (2008). Children in medical research: Access versus protection. New York, NY: Oxford University Press.

Rossi, W. C., Reynolds, W., \& Nelson, R. M. (2003). Child assent and parental permission in pediatric research. Theoretical Medicine, 24, 131-148.

Swartling, U., Hansson, M. G., Ludvigsson, J., \& Nordgren, A. (2011). "My parents decide if I can. I decide if I want to." Children's views on participation in medical research. 
Journal of Empirical Research on Human Research Ethics, 6(4), 68-75.

Swartling, U., Helgesson, G., Hansson, M. G., \& Ludvigsson, J. (2009). Split views among parents regarding children's right to decide about participation in research: A questionnaire survey. Journal of Medical Ethics, 35, 450-455.

Swartling, U., Helgesson, G., Ludvigsson, J., \& Hansson, M. G. (2008). Parental authority, research interests, and children's right to decide in medical research-An uneasy tension? Clinical Ethics, 3, 69-74.

Tait, A. R., Voepel-Lewis, T., \& Malviya, S. (2003). Do they understand? (Part II): Assent of children participating in clinical anesthesia and surgery research. Anesthesiology, 98, 609-614.

Tercyak, K. P., Swartling, U., Mays, D., Johnson, S. B., \& Ludvigsson, J. (2013). Behavioral science research informs bioethical issues in the conduct of large-scale studies of children's disease risk. AJOB Primary Research, 4(3), 4-14.

Varma, S., Jenkins, T., \& Wendler, D. (2008). How do children and parents make decisions about pediatric clinical research? Journal of Pediatric Hematology/Oncology, 30, 823-828.

Wendler, D., Abdoler, E., Wiener, L., \& Grady, C. (2012). Views of Adolescents and parents on pediatric research without the potential for clinical benefit. Pediatrics, 130, 692-696.

Wendler, D., \& Jenkins, T. (2008). Children's and their parents' views on facing research risks for the benefit of others. Archive of Pediatrics \& Adolescence Medicine, 162, 9-14.

\section{Author Biographies}

Ulrica Swartling is an assistant professor in medical ethics at Lund University. She has for many years conducted empirical research on research ethical aspects, with a special interest in children and screening for type 1 diabetes. She served as the principal investigator for this project and, in this capacity, was responsible for overseeing all aspects of this article.

Gert Helgesson is an associate professor in medical ethics at Stockholm Center for Healthcare Ethics, Karolinska Institutet. His main research area is research ethics, including scientific misconduct, research on children, informed consent, and other autonomy issues. He contributed significantly to data analysis and interpretation as well as to the reporting of findings.

Johnny Ludvigsson is a professor emeritus of pediatrics at Linköping University, and is the principal investigator (PI) of the ABIS study. He was primarily involved with data collection and contributed to the reporting and interpretation of findings.

Mats G. Hansson is a professor of biomedical ethics and the director of the Center for Research Ethics and Bioethics at Uppsala University. He has published extensively in bioethics with a focus on informed consent issues, ethical aspects of biobank research, and clinical ethics. He contributed to data interpretation and to the reporting of findings.

Anders Nordgren is a professor of bioethics and the director of the Center for Applied Ethics at Linköping University. He has published mainly on ethical issues raised by human genetics and animal experimentation. He served as a co-principal investigator for this project and contributed significantly to data analysis and interpretation as well as to the reporting of findings. 